\title{
VHF/UHF radar observations of tropical mesoscale convective systems over southern India
}

\author{
Karanam Kishore Kumar ${ }^{1}$, A. R. Jain ${ }^{2}$, and D. Narayana Rao ${ }^{3}$ \\ ${ }^{1}$ Space Physics Laboratory, Vikram Sarabhai Space Center, Trivandrum 695022, India \\ ${ }^{2}$ National Physical Laboratory, New Delhi, India \\ ${ }^{3}$ National MST Radar Facility, P.B. 123, Tirupati-517502, India
}

Received: 9 December 2003 - Revised: 4 January 2005 - Accepted: 10 May 2005 - Published: 28 July 2005

\begin{abstract}
Several campaigns have been carried out to study the convective systems over Gadanki $\left(13.5^{\circ} \mathrm{N}, 79.2^{\circ} \mathrm{E}\right)$, a tropical station in India, using VHF and UHF radars. The height-time sections of several convective systems are investigated in detail to study reflectivity, turbulence and vertical velocity structure. Structure and dynamics of the convective systems are the main objectives of these campaigns. The observed systems are classified into single- and multi-cell systems. It has been observed that most of the convective systems at this latitude are multi-cellular in nature. Simultaneous VHF and UHF radar observations are used to classify the observed precipitating systems as convective, intermediary and stratiform regions. Composite height profiles of vertical velocities in these regions were obtained and the same were compared with the profiles obtained at other geographical locations. These composite profiles of vertical velocity in the convective regions have shown their peaks in the mid troposphere, indicating that the maximum latent heat is being released at those heights. These profiles are very important for numerical simulations of the convective systems, which vary significantly from one geographical location to the other.
\end{abstract}

Keywords. Meteorology and atmospheric dynamics (Mesoscale meteorology; Convective processes) - Radio science (Remote sensing)

\section{Introduction}

A vast majority of recent observational studies of mesoscale systems have been signifying a renewed interest in tropical mesoscale convective systems (TMCS) and their impact on general atmospheric circulation and hence the global climate. Tropical convection transports and redistributes the largescale fields of heat, moisture, mass and momentum throughout the atmosphere. The redistribution of various quantities affects the troposphere composition and its chemistry,

Correspondence to: Karanam Kishore Kumar

(kishore_nmrf@yahoo.com) especially the tropospheric air quality. They also alter the flow fields and thermodynamic stratification within the atmosphere, such that they affect subsequent convective activity.

The energy transformations associated with the change in phase of water in these systems, as well as the strong updrafts and down drafts, which often extend throughout the troposphere, can have an important effect on the dynamics and energetics of large-scale atmospheric systems. Hartmann et al. (1984) showed that the walker circulation is sensitive to the vertical distribution of latent heat release in the TMCS. The latent heat released from precipitation gives rise to ascending motion in the tropical atmosphere. In fact, virtually all ascents in the tropics are associated with deep convection. Such an ascent is closely tied to horizontal flows in the tropics by mass continuity. So, deep convective flows affect the atmosphere far from the convection itself. Heat released in these systems plays a fundamental role in heating of the large-scale environment (Houze, 1989) and can generate mesoscale circulations (De Maria, 1985; Hack and Schubert, 1990; Johnson, 1992) which are very important from a climatological standpoint. Houze $(1982,1989)$ showed that the net heating produced by a mature TMCS is predominantly in the upper troposphere, with little net heating below $4 \mathrm{~km}$. The stratiform region and cumulus towers within a TMCS both contribute to the heating profile. In addition, the cloud cover associated with convection strongly affects both surface heating and other radiative processes. Mapes (1993) studied the linear transient response of a stratified fluid layer to a localized heat source. He idealized the vertical profile of diabatic heating as the sum of a convective component maximum in the mid troposphere and a stratiform component with heating in the upper troposphere and cooling in the lower troposphere. He suggested that this would favor additional convection in the vicinity of old convection due to increased column-integrated Convective Available Potential Energy (CAPE) and decreased convective inhibition. Nicholls et al. (1991) reported on thermally forced gravity waves, which are of prime interest to the atmospheric community. To the present day, the exact representation of the 


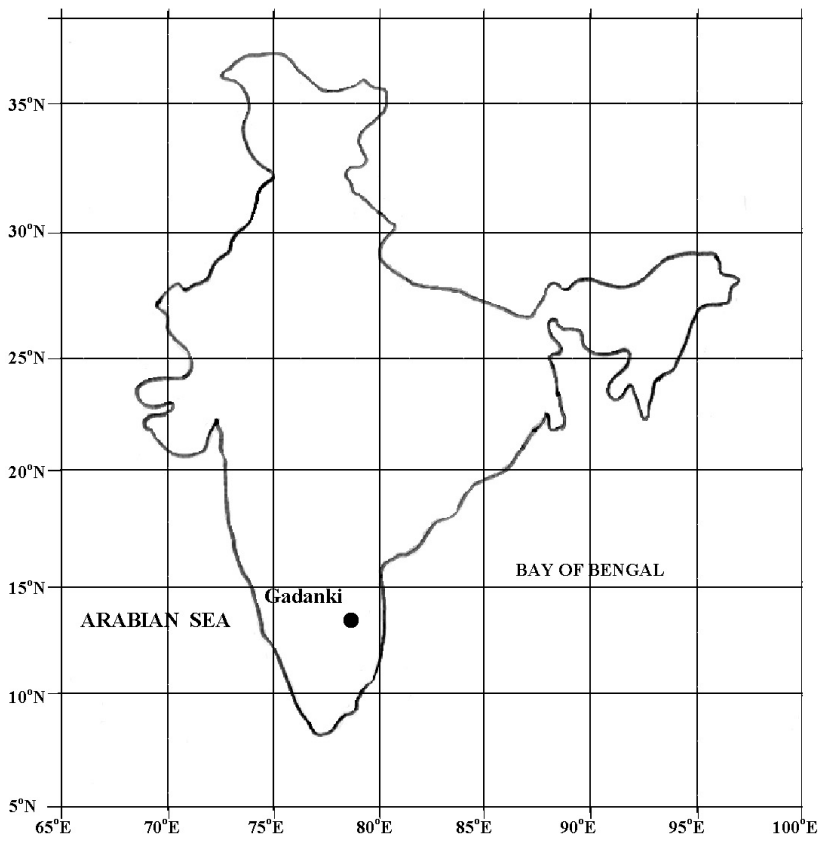

Fig. 1. A map showing the location of observational site.

distribution of diabetic heating is one of the greatest unmet needs in numerical models. So, there is a great need for developing the global climatology of convective systems and to understand the most significant physical process associated with these systems. This would allow to parameterize the convective systems exactly for improved numerical weather models.

Various techniques have been used to study the dynamics of TMCS, such as aircraft, radiosonde, satellites and Doppler radars. Among all these platforms, Doppler radars have been providing a wealth of information about such systems. Doppler radars are very effective tools for studying the subgrid processes, such as TMCS, and provide a means to visualize the structure of convective systems. The need of global climatology of convective systems has motivated the Doppler radar observations. Even though such climatology can be studied ultimately by the satellite observations, the vertical structures of these systems can be obtained only by radars. The most exciting potential of the Doppler radar is to observe vertical air motions in the convective systems, which is a critical quantity for tropical convection parameterization in numerical models. VHF Doppler radars, primarily designed for wind profiling, have been used to explore clear air and hydrometer structures in tropical convective systems (Balsley et al., 1988; Zipser et al., 1990; Gage, 1990). These radars can directly monitor winds, waves and turbulence both in convective systems, as well in the clear air surrounding the systems. Many studies at various geographical locations reported on these valuable vertical velocity structures of the convective systems, which showed considerable variability from place to place (Houze, 1982; Cifelli and Rutledge, 1994). In addition, VHF radars are capable of measuring both hydrom- eteors velocities as well as clear air motions, which can be used to derive the drop size distributions (Wakasugi et al., 1986, 1987; Rajopadhyaya et al., 1998). These systems are sensitive to the hydrometeors, only when the precipitation is moderate to heavy. On the other hand, UHF radars are very sensitive to hydrometeors and provide continuous record of the hydrometeors in the convective systems. These radars reveal the vertical structure of convective systems with sufficient details to diagnose and classify them as stratiform and convective regions (Gage et al., 1994, 1996; Ecklund et al., 1995; Williams et al., 1995; Rao et al., 1999). Simultaneous observations of VHF and UHF radars provide a means to understand the dynamics of both clear air and hydrometeors in the convective system (Rajopadhyaya et al., 1998). Using the observational facilities available at Gadanki, a few studies were made to explore the TMCS over this tropical station (Rao et al., 1999, 2001; Jain et al., 2000, Dhaka et al., 2001).

Several convection campaigns have been carried out since 1996 at the Gadanki Radar Facility to explore the TMCS. Figure 1 shows a map locating the observational site. All these campaigns have been carried out in two regimes, one in south-west monsoon (June-September) and another in the north-east monsoon (October-November). VHF and UHF radar observations of TMCS have been studied extensively to understand various aspects. The height-time sections of echo power (in terms of signal-to-noise ratio), turbulence intensity (in terms of spectral width) and vertical velocity of various types of convective systems are discussed. VHF/UHF radar observations have been used to classify the observed systems into convective, intermediary and stratiform regions. The composite height profiles of vertical velocities in these regions are computed from VHF radar observations for the first time at this latitude. The central objective of this paper is to give an idea of the various types of convective systems occurring at this latitude and to study their height-time structures.

\section{Campaigns and database}

During the campaign periods, all the collocated facilities (VHF radar, UHF radar, Optical Rain Gauge, Disdrometer and Automatic weather Station) available at Gadanki were operated to monitor the passage of convective systems. For the present study, data collected from the three instruments viz. VHF radar, UHF radar and disdrometer are used. VHF radar located at Gadanki operates at $53 \mathrm{MHz}$ (signal wavelength is $5.66 \mathrm{~m}$ and hence this instrument detects the backscattered echoes from irregularities of $\sim 3 \mathrm{~m}$ ), with an average power aperture product of $\sim 7.7 \times 10^{8} \mathrm{Wm}^{2}$ and an altitude resolution of $150 \mathrm{~m}$ in the vertical direction. This system uses the phased array antennas $(32 \times 32)$ for transmitting and receiving the signals using the duplexer. The radar system details are given by Jain et al. (1994) and Rao et al. 1995. UHF wind profiler, installed at Gadanki for boundary layer studies, operates at $1357.5 \mathrm{MHz}$ and system details are given by Krishna Reddy et al. (2001). Simultaneous VHF 
(a)

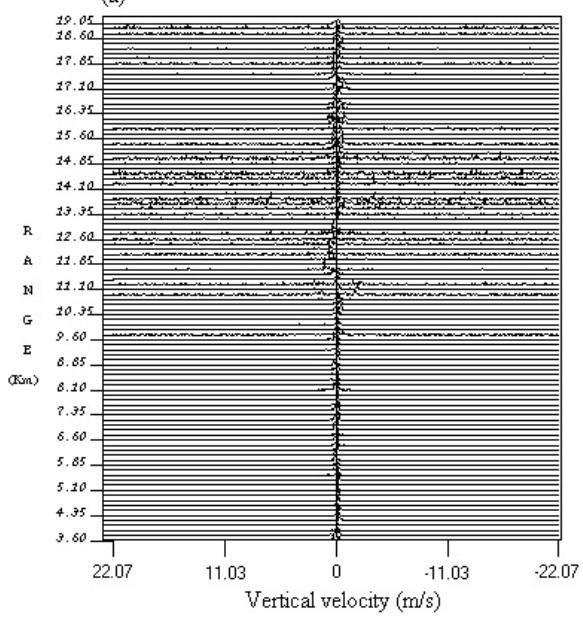

(b)

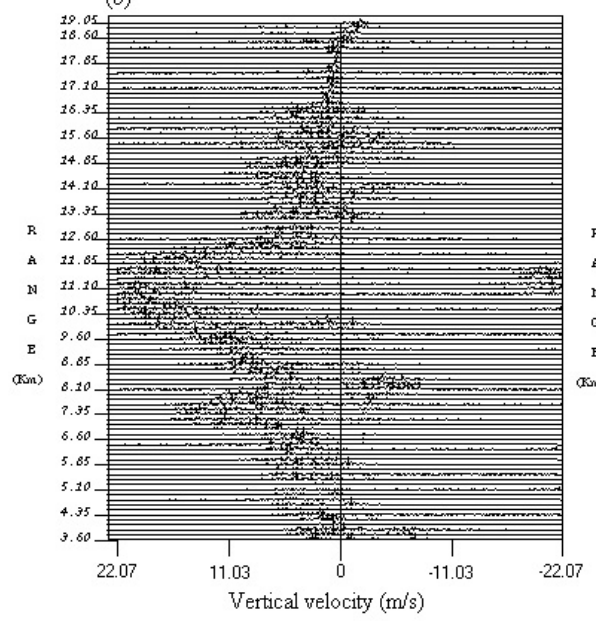

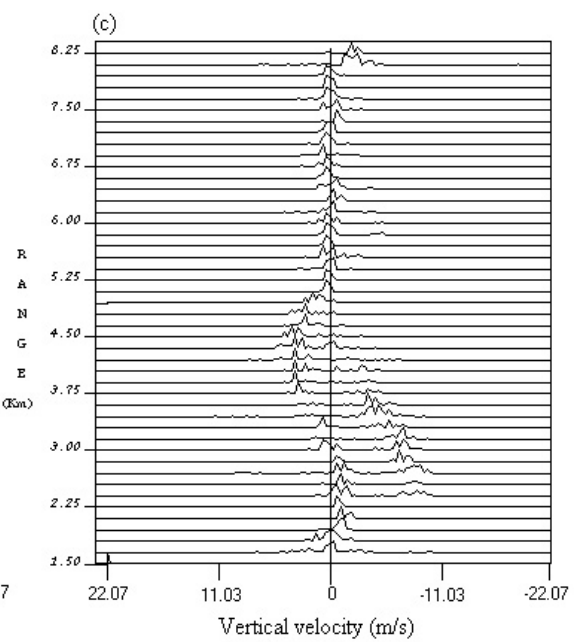

Fig. 2. Typical VHF radar power spectra obtained in (a) clear-air, (b) and (c) in convection environments on 25 May 2002.

and UHF radar observations are available only during August 1997-September 2001. After this period, due to some technical problems the UHF radar was not operated. Disdrometer observations are available from September 1997-June 2002. For most of the observations of TMCS were carried out in a campaign mode. However, some observations, which were taken accidentally, are also included in the present study. Most of the time, continuous measurements of clear-air vertical velocity, which is one of the exciting potentials of VHF radar, have been given priority during the passage of the convective systems.

All the data collected during these observations are analyzed to obtain the radar reflectivity (in terms of signal-tonoise ratio), spectral width and vertical velocities. Obviously, there are many data sets collected during all of these campaigns. These data sets essentially contain observations of a variety of convective systems occurring at this latitude. Most of the mesoscale convective systems occurring at this latitude can be broadly classified as convective, intermediary or stratiform regions. Again, the convective regions can be classified subjectively as (a) shallow convection, where the vertical velocity cores will reach as high as $5-7 \mathrm{~km}$; this is consistent with the notation that these shallow cells are associated with warm rain processes; (b) deep convective systems, which have vertical velocity cores extending as high as $\sim 15-16 \mathrm{~km}$. These deep convective systems are further classified into single- and multi-cell systems according to the vertical velocity core characteristics. It is very important to note here that the definition of a cell in the present study is taken as a distinct updraft. The definition of a cell is emphasized here, because usually a cell is defined in terms of Doppler weather radar (which is sensitive to precipitation) observed reflectivity maxima. Presumably, comparable numbers of updrafts are associated with the observed reflectivity maxima. VHF radars are not that sensitive to precipitation and hence the distinct updraft core is regarded as a cell in the present observations. In the present study, convective systems having a single vertical velocity core are regarded as single-cell systems, while the systems having more than one vertical velocity core are regarded as a multi-cell system.

The stratiform regions are those where the dominant cells are decaying and a more stratiform circulation of an updowndraft couplet is visible, although the amplitude of the vertical motion is still several meters per second. These stratiform regions are well known for the existence of radar bright bands, which will be discussed in the later part of the paper. Thus, the present data set has all the stages of the growth of convective systems, with examples of shallow convection only a few kilometers deep, more intense deep cells reaching as high as tropopause level and cells that are transforming into stratiform mesoscale up-/downdraft pattern. These classifications are very subjective and cannot be generalized. Out of all the observed systems, height-time sections of some selected events are presented in this paper. Almost all convective systems observed during the various campaigns fall into one of the above classifications.

\section{Results and discussion}

Figure 2a shows typical VHF radar vertical beam power spectrum obtained during quiet weather conditions. This spectrum shows vertical velocities of the order of a few tens of $\mathrm{cm} / \mathrm{s}^{-1}$. Figures $2 \mathrm{~b}$ and $\mathrm{c}$ show the power spectra obtained during the passage of a deep convective system. The power spectrum in the Fig. $2 \mathrm{~b}$ shows large vertical velocities of the order of several $\mathrm{ms}^{-1}$, as indicated by the large Doppler shifts. These power spectra are estimated using the in-phase and quadrature phase data collected from the VHF radar vertical beam observations. The positive velocities indicate upward motion and negative velocities indicate downward. Another substantial difference in quiet weather conditions and convective system power spectra is the Doppler 


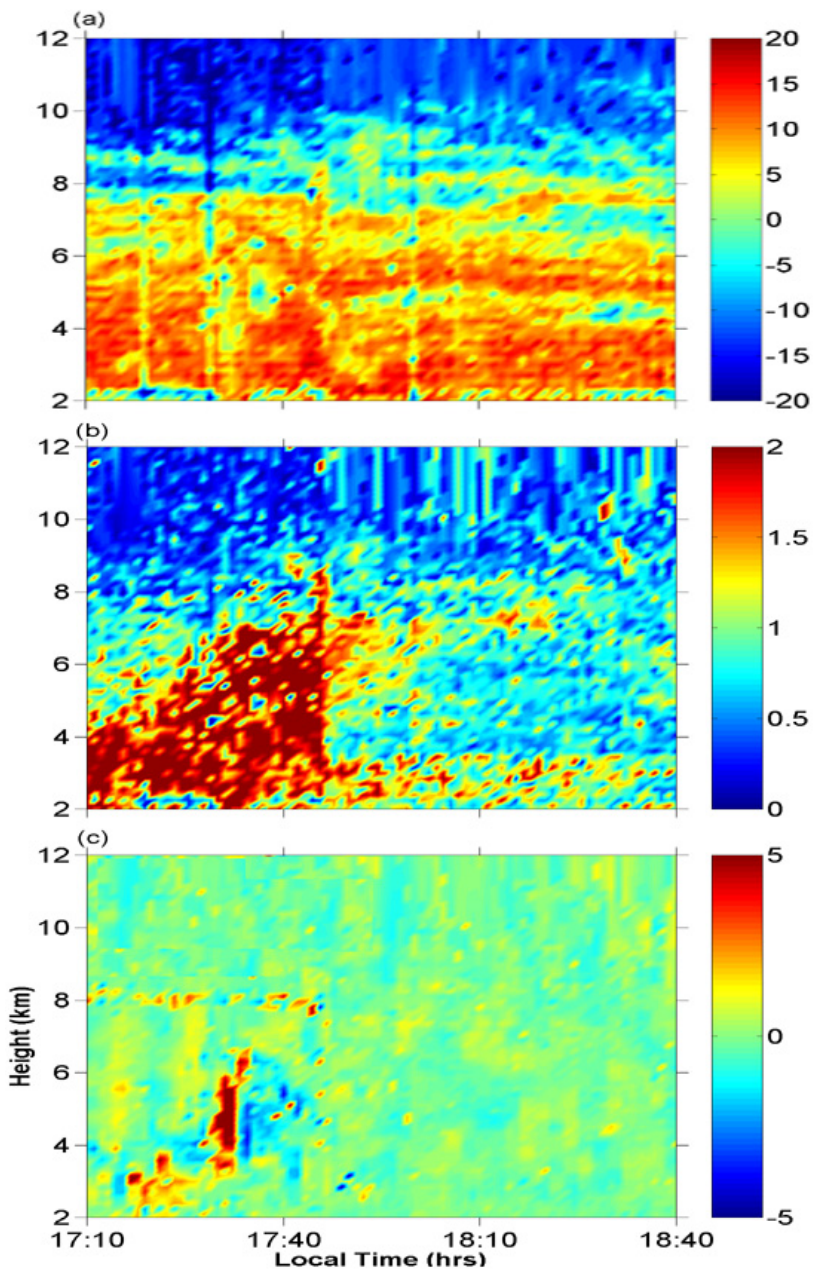

Fig. 3. Height time sections of (a) VHF radar signal-to-noise ratio $(\mathrm{dB})$, (b) spectral width $(\mathrm{m} / \mathrm{s})$ and (c) vertical velocity $(\mathrm{m} / \mathrm{s})$ for a shallow convective system, as observed on 18 August 1999.

widths, which are larger for the spectrum obtained in the convective systems as compared to the spectrum obtained in quiet weather conditions.

From Fig. 2c, it is very interesting to note the two traces of echoes in the height region of $2.4-4.5 \mathrm{~km}$. These traces correspond to clear-air and hydrometeors. The extreme righthand side trace is the hydrometeor fall velocity spectrum due to Rayleigh scattering and the other is the clear-air velocity spectrum due to Bragg scattering. In the present study, only clear-air echoes have been used to explore the structure of the observed convective systems and enough care has been taken to avoid the hydrometeor echoes during the analysis of the present data, as suggested by Rao et al. (1999). For most of the time, the hydrometeor and clear-air echoes are well separated in frequency domain, and only clear-air echoes have been chosen while calculating the moments. However, these double traces were not present in all the data sets, as the VHF radars are sensitive to hydrometeors only if they occur in the form of heavy rainfall. Some of the spectra (very few) which are more contaminated with hydrometeor echoes, are not in-

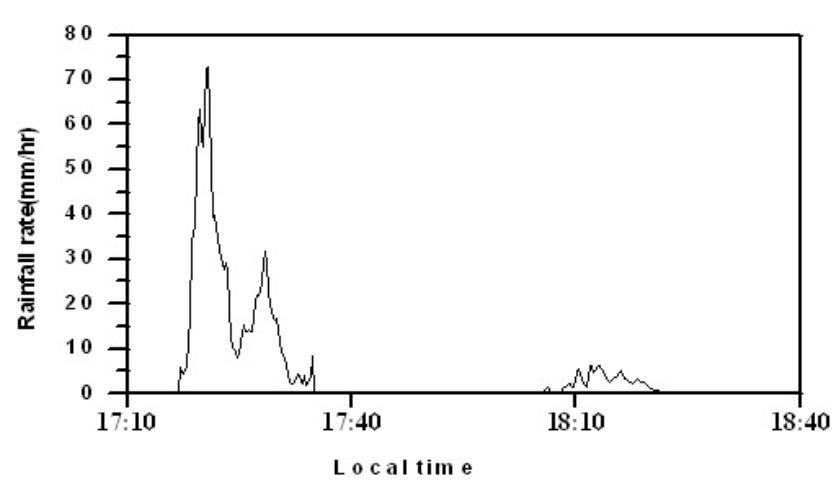

Fig. 4. Rainfall measurements as observed on 18 August 1999.

cluded in the analysis. In the present data set, only a limited number of spectra have these double traces and do not disturb the present study, as the adaptive technique is used to analyze the data set (Anandan, 1996).

\subsection{VHF radar observed height-time sections of convective systems}

In this paper, height-time sections of each convective event are presented in three panels. The top panel shows the radar reflectivity in terms of signal-to-noise ratio in $\mathrm{dB}$, the middle panel shows the turbulence intensity in terms of radar spectral width in $\mathrm{ms}^{-1}$, and the bottom panel shows the vertical velocity in $\mathrm{ms}^{-1}$. Only vertical beam observations are used for the construction of height-time sections, and the time given is local time ( $\mathrm{LT}=\mathrm{UT}+05: 30 \mathrm{~h})$. All the rainfall measurements used for the present study are taken from the disdrometer observations.

\subsubsection{Shallow convection}

The shallow convection events associated with the warm rain process are very localized and are a common phenomena over Gadanki. Typical height-time sections of these systems observed on 18 August 1999 are shown in Fig. 3. The radar reflectivity pattern for this case shows echo tops reaching up to $\sim 9 \mathrm{~km}$. These observations were taken with with a $1-\mu \mathrm{s}$ pulse width and hence the height coverage was up to $\sim 12 \mathrm{~km}$ only. The height-time section of spectral width shows enhanced turbulence during 17:10-17:50 h. The vertical extent of this pattern is also limited in height, which also confirms the shallowness of the observed system. The bottom panel of this figure shows the height time section of vertical velocity. This plot readily shows the vertical velocity cores embedded in the system. Even though this plot shows more than one vertical velocity core, a well-defined narrow core can be seen during 17:20-17:40. The vertical extent of this core is of $\sim 3 \mathrm{~km}$ and it is reaching just above the freezing level. At this latitude, the freezing level occurs around $\sim 4-5 \mathrm{~km}$ (obtained from the radiosonde ascents from Chennai). Figure 4 shows the rainfall measurements during the passage of the system over the radar site. These figures represent a typical 


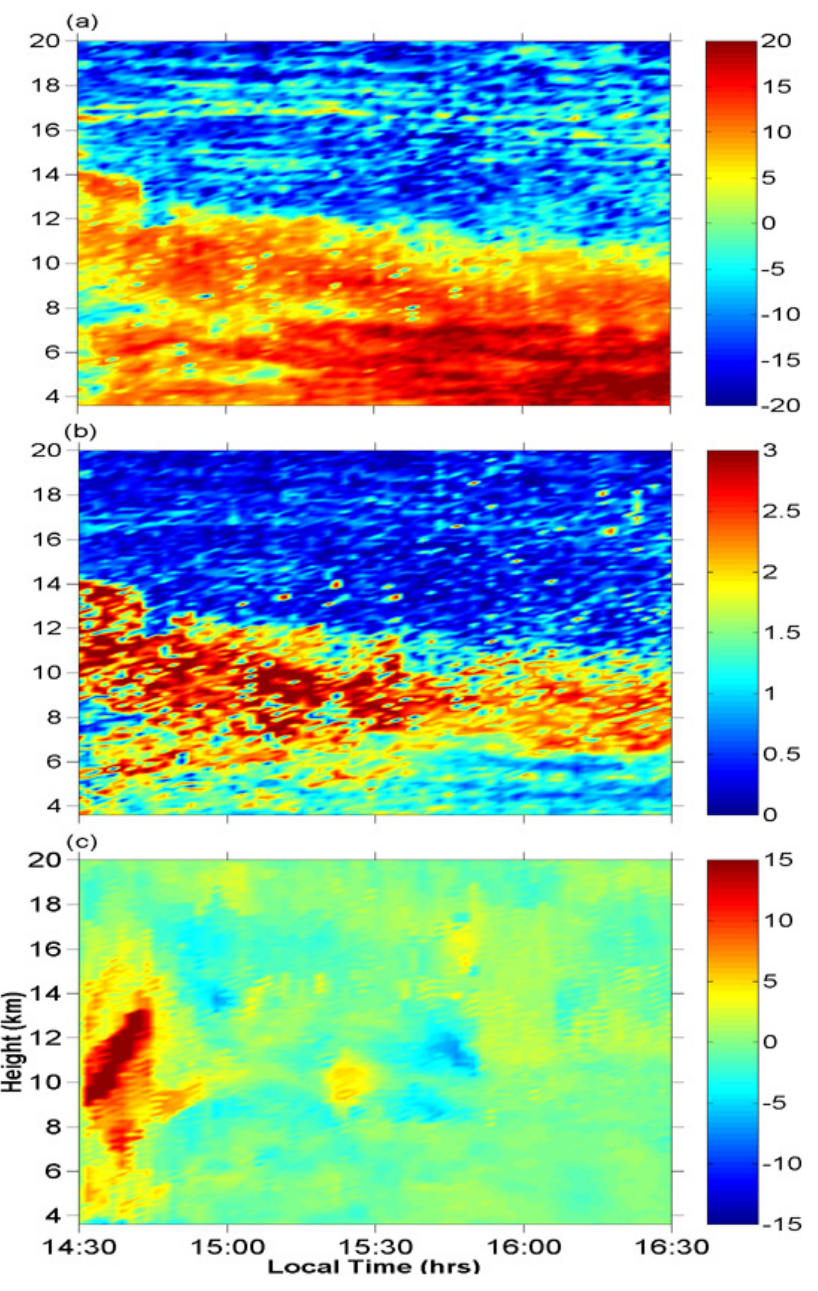

Fig. 5. Height-time sections of (a) VHF radar signal-to-noise ratio (dB), (b) spectral width $(\mathrm{m} / \mathrm{s})$ and (c) vertical velocity $(\mathrm{m} / \mathrm{s})$ for a single-cell convective system ,as observed on 25 May 2002.

example of a shallow convection. Even though these systems are important from a climatological standpoint, as they affect the radiation budgets and significantly account for the observed rainfall, they are less important as compared to the deep convective systems for which the tropical atmosphere has a special consideration.

\subsubsection{Deep convection}

As mentioned in Sect. 2, deep convection events are further classified into single- and multi-cell events. Multi-cell event are very common at this latitude. This type of events dominates the present data set. There was a problem in categorizing the observed events as single- or multi-cell events, because the present radar observational area is limited by its beam width and tilting angle of the beams. Only those parts of the system can be sampled which pass over the radar site. However, the present study does not aim at the statistical occurrence of the particular type of system and rather focuses on the structure of various types of systems.

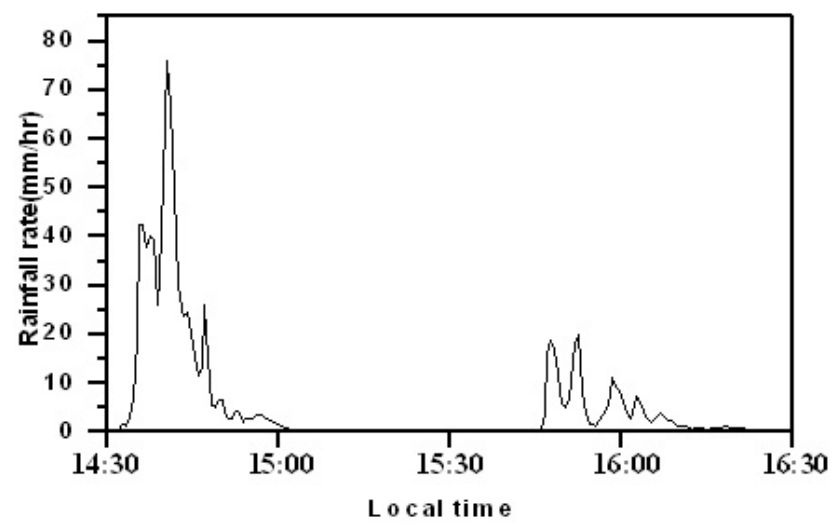

Fig. 6. Rainfall measurements as observed on 25 May 2002.

Figure 5 shows the height-time sections of radar reflectivity, spectral width and vertical velocity for a single-cell event, as observed on 25 May 2002. The reflectivity pattern shows an upwelling pattern in the beginning of the event with echo tops reaching $\sim 15 \mathrm{~km}$. The spectral width pattern is following the reflectivity pattern, confirming the dominancy of the turbulence in giving rise to the enhanced reflectivity. The bottom panel clearly shows a single vertical velocity core with a maximum velocity of $\sim 15 \mathrm{~ms}^{-1}$ during 14:30-14:50 h. The vertical extent of this core is of $\sim 8 \mathrm{~km}$. The rainfall measurements during the passage of this system are shown in Fig. 6, which shows a peak of $75 \mathrm{mmhr}^{-1}$. Thus, this plot reveals the structure of a typical single-cell convective system occurring at this latitude.

The second kind of deep convective system consists of multi-cells having more than one vertical velocity core. As mentioned earlier, the present data set contains several examples of this kind and most of the height-time sections look alike. Thus, only two such systems are discussed here. Figure 7 shows the height-time sections of a typical multi cell system, which passed over the radar site on 15 September 2001. The reflectivity and spectral width plots show elevated patterns up to the height region of $\sim 16 \mathrm{~km}$. It is exciting to note that the echo tops are reaching the tropopause level (on this day the tropopause height was $16.5 \mathrm{~km}$, which is derived from Chennai radiosonde observations). The vertical velocity plot readily shows three well separated vertical velocity cores with different vertical extents, which make it a multi-cell event. Apart from these three cores, some more weak and vaguely defined cores can be seen from this plot. The maximum vertical velocity observed on this day is $\sim 10 \mathrm{~ms}^{-1}$. Figure 8 shows the rainfall observations during the passage of the system, which shows a peak of $\sim 170 \mathrm{mmhr}^{-1}$. Figure 9 also represents a height-time section of a multi cell event observed on 10 June 1996. Almost all the features are more or less similar to that of 15 September 2001 event. In this event, the echo tops are not reaching up to the tropopause level and are limited to a height of $\sim 14 \mathrm{~km}$. Two well-defined layered structures can be seen from this plot in the height region of $17-18 \mathrm{~km}$. The lower 


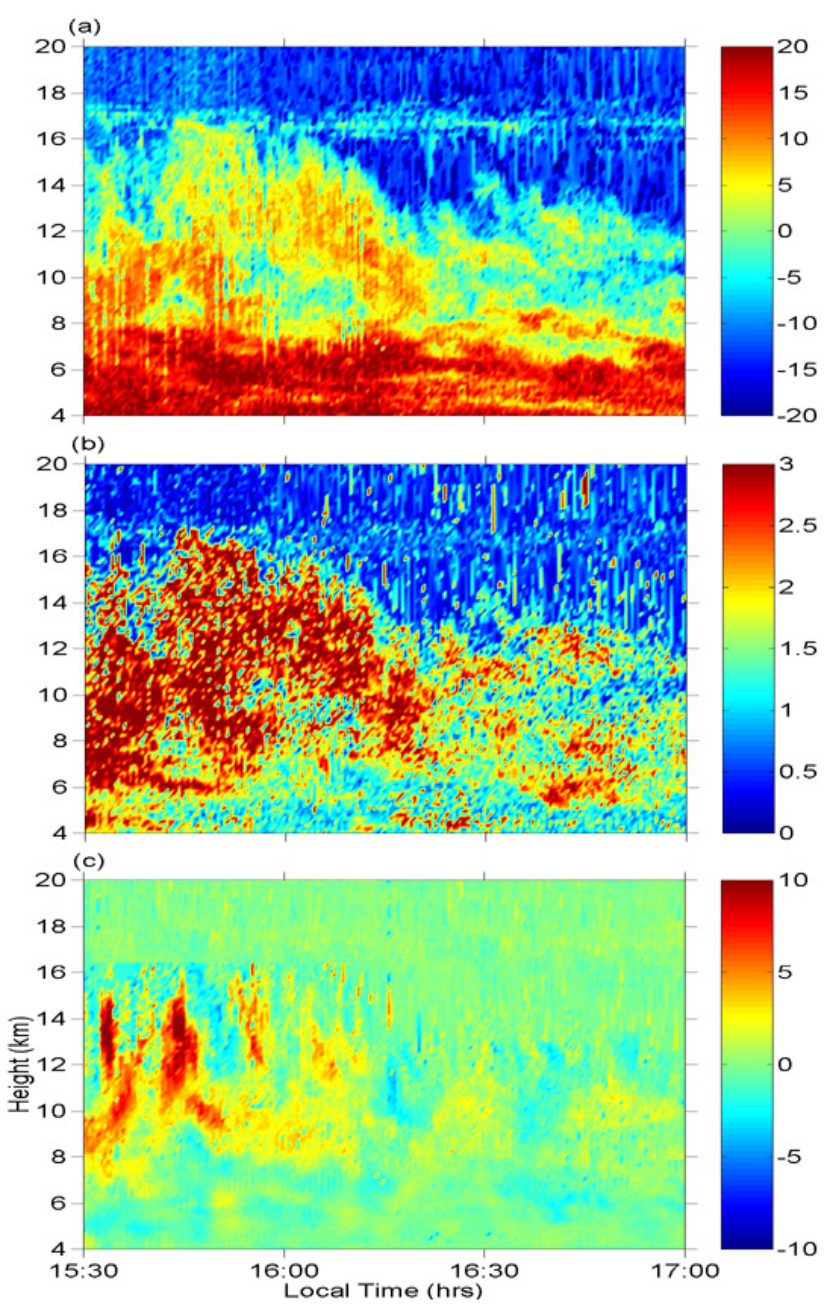

Fig. 7. Height-time sections of (a) VHF radar signal-to-noise ratio (dB), (b) spectral width $(\mathrm{m} / \mathrm{s})$ and (c) vertical velocity $(\mathrm{m} / \mathrm{s})$ for a multi cell convective system, as observed on 15 September 2001.

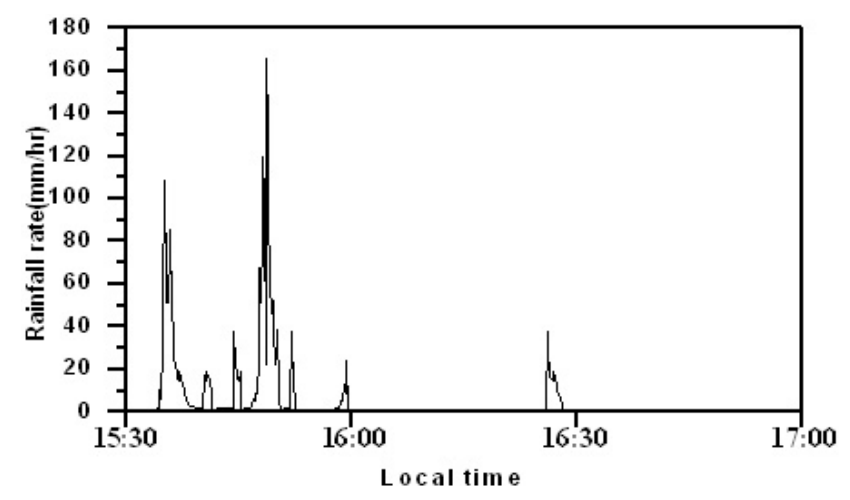

Fig. 8. Rainfall measurements as observed on 15 September 2001.

layer corresponds to the tropopause. In this event the spectral width pattern also follows the reflectivity pattern and the vertical velocity plot shows closely organized vertical velocity cores. The maximum vertical velocity observed in this
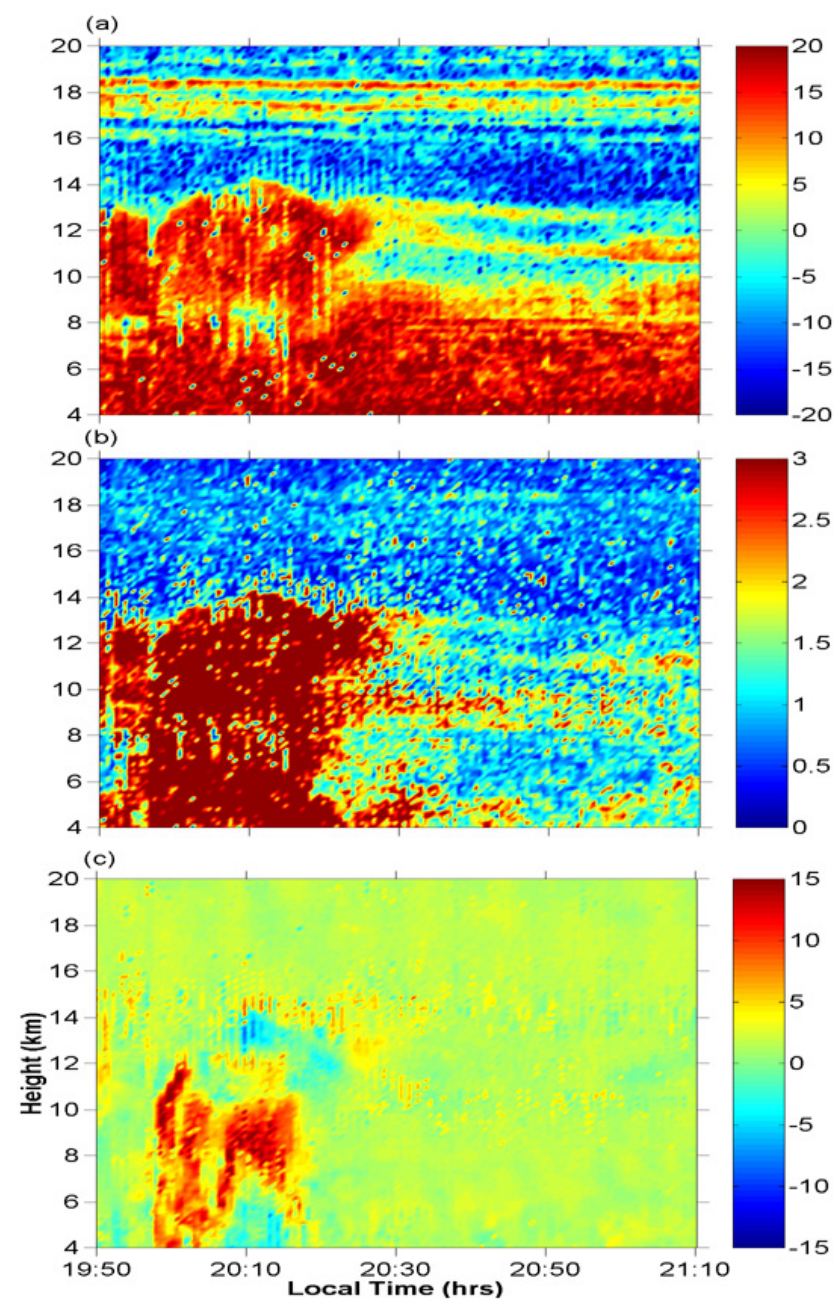

Fig. 9. Height-time sections of (a) VHF radar signal-to-noise ratio (dB), (b) spectral width $(\mathrm{m} / \mathrm{s})$ and (c) vertical velocity $(\mathrm{m} / \mathrm{s})$ for a multi cell convective system, as observed on 10 June 1996.

system is $\sim 15 \mathrm{~ms}^{-1}$, which represents an intense convection event. These vertical velocity cores play a vital role in producing precipitation at the ground.

Most of the height-time sections of vertical velocities of the multi-cell convective systems observed in the present data set show one common feature. The vertical velocity cores in these systems are accompanied by downdrafts. These upper level downdrafts (well above the freezing level) adjacent to the updrafts can be attributed to sublimation and condensate loading (Knupp, 1987). Other possibilities for these downdrafts include a blocking effect (Lemon and Doswell, 1979), but the downdrafts occur on both sides of the upward cores and other studies show a complicated relationship between the upward and downward cores (Heymsfield and Schotz, 1985; Yuter and Houze, 1995a). These studies suggest that the upper-level cores may be driven, at least in part, by pressure perturbations induced by the strong updrafts (Yuter and Houze, 1995b) i.e. many of the downward cores adjacent to the upward cores arise from a dynamical response. These 

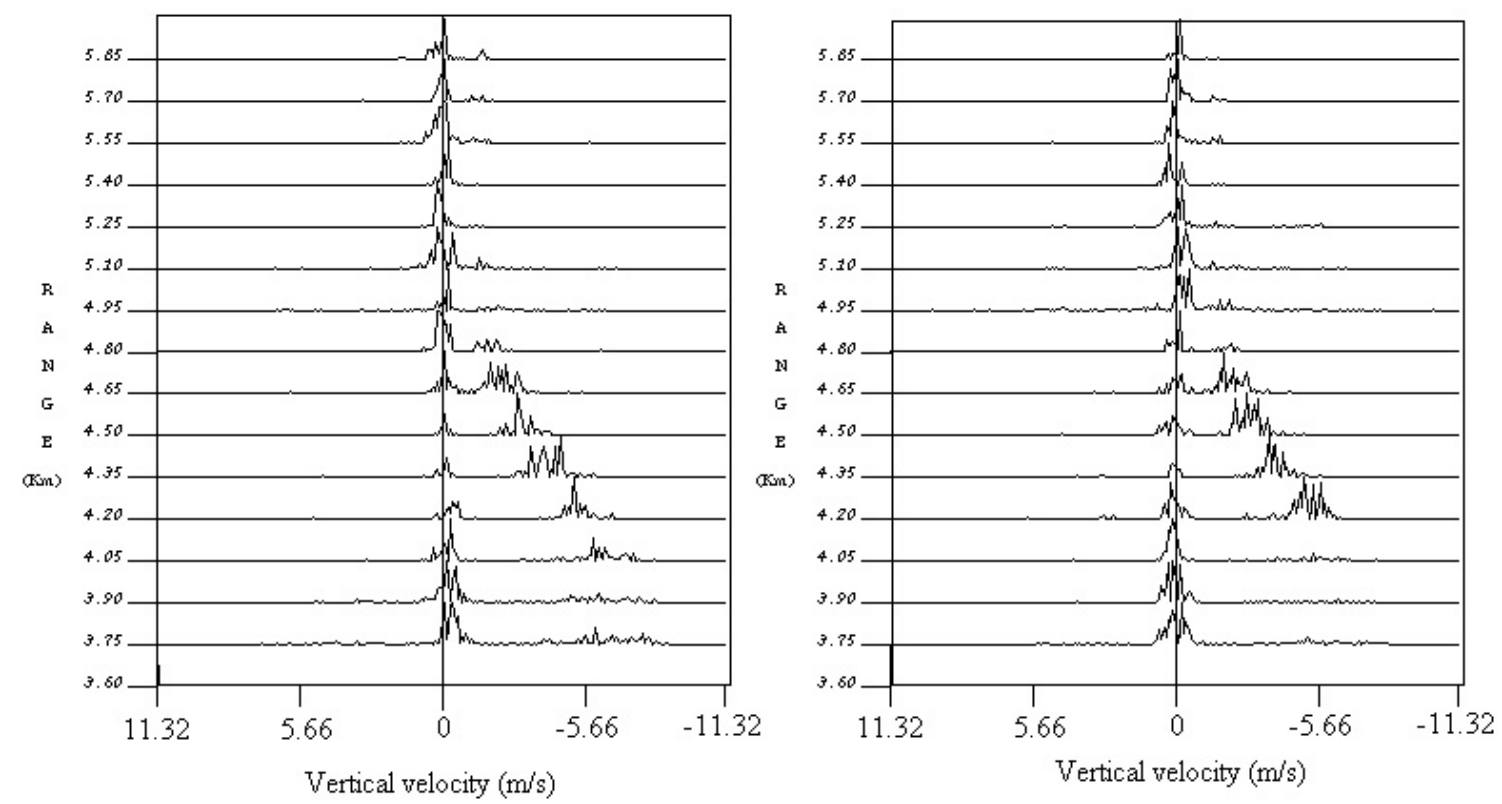

Fig. 10. Typical VHF radar power spectra observed in stratiform regions of a mesoscale convective system at two different times on 4 November 1997.

deep downward cores also provide indirect support for the observation of thermally buoyant downdrafts observed by aircraft (Jorgensen and LeMone, 1989; Lucas et al., 1994). These pressure perturbations also affect the updrafts themselves (Trier et al., 1997). The other category of downdraft, which is occurring below the freezing level (low level downdraft), is mainly precipitation/evaporatively driven.

\subsection{Height-time sections of stratiform regions}

The present data set also contains cases where the convective cells are transformed into stratiform regions, which can be regarded as the old convection areas. When atmospheric convection is young and vigorous, it contains updrafts having velocities of the order of several $\mathrm{m} / \mathrm{s}$, as shown in the previous sections. As the convection weakens, the precipitation associated with the cells takes on a layered structure. However, the upward vertical air motions in the region of weakened convection are strong enough to allow precipitation particles to grow by vapor diffusion, but too weak to support high concentrations of cloud liquid water; therefore, growth by riming is not as effective as when the updrafts are stronger. These stratiform regions occupy a considerable area in the tropical mesoscale systems (Houze, 1997) and play a vital role in producing the precipitation. These stratiform regions show the characteristic VHF radar spectra, as shown in Fig. 10. From these spectra, it can be noted that there are two distinct echo traces; one is close to zero Doppler (corresponding to clear-air) and another one starting at $4.65 \mathrm{~km}$ and decending down. The latter trace shows fall velocities of the order of $\sim 6 \mathrm{~ms}^{-1}$ (corresponding to hydrometeors). These spectra can be used to separate the stratiform regions from the convective regions in the TMCS. Fig-
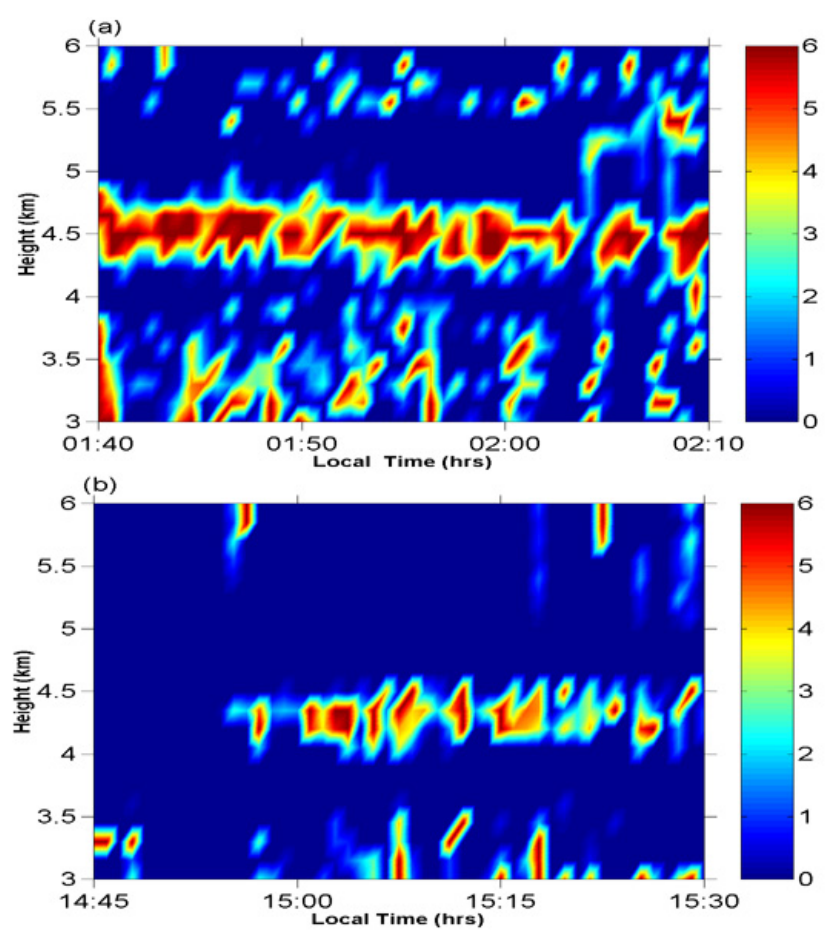

Fig. 11. Height-time sections of VHF radar signal-to-noise ratio (dB) revealing the radar bright band as observed on (a) 16 October 1997 and (b) 4 November 1997.

ures $11 \mathrm{a}$ and $\mathrm{b}$ show the height-time sections of radar reflectivity as observed on 16 October 1997 and 4 November 1997, respectively. These represent the reflectivity pattern of a typical stratiform region. The striking feature of this figure is the enhanced radar reflectivity at $\sim 4.5 \mathrm{~km}$, which is 

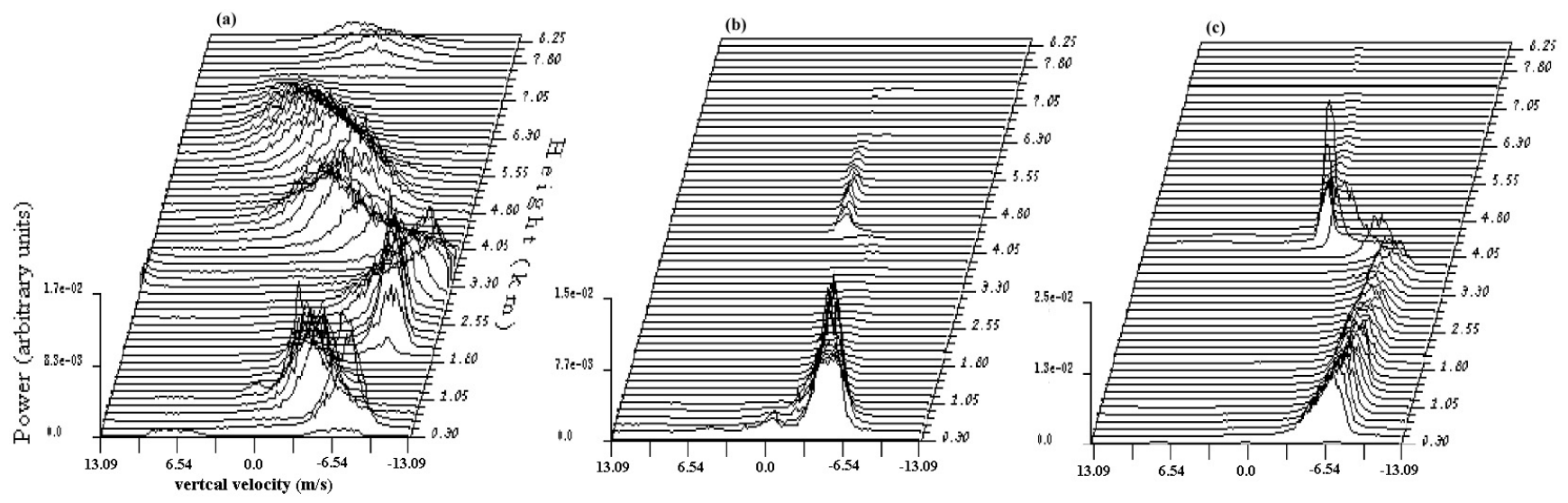

Fig. 12. Typical UHF radar power spectra observed in (a) convective, (b) intermediary and (c) stratiform regions of a mesoscale convective system (21 June 2000).

well known as the radar bright band. Several studies in the past reported a bright band in the stratiform regions of the convective systems (Houze, 1993). Houze (1997) attributed the enhanced echo power at the melting layer to two mechanisms: (1) melting particles are large aggregates of ice crystals and reflectivity is proportional to the sixth power of the particle dimension; (2) the refractive index of melting ice is higher than that of non melting ice. In addition, when the ice particles melt, their fall speeds increase and the particles evacuate the melting layer rapidly in a vertically divergent fashion, producing a decreased concentration of particles below the melting layer. These factors combine to produce a pronounced bright band of enhanced reflectivity in a shallow layer centered just below the $0^{\circ} \mathrm{C}$ level. Thus, the presence of a bright band is an unambiguous indicator of a stratiform region. However, the absence of a bright band does not imply the absence of a stratiform region. A bright band will not be observed unless the vertical resolution of the radar is sufficiently fine to delineate the band. Thus, the ability to detect the bright band is a function of the characteristics of the radar rather than the storm.

Most of the deep convective systems observed over the site show the presence of both the convective and the stratiform regions. The height-time sections of deep convective systems presented in this paper essentially show this fact. In particular, the height- time sections of the vertical velocity show the two regions, one in which the large vertical velocity cores are seen and the other one in which weak upward and downward motions are seen. However, UHF radar observations can better classify the convective systems into respective regions, which are discussed in the following section.

\subsection{Classification of convective systems using VHF/UHF radar observations}

Even though VHF radars give valuable information about the convective systems, they are not sensitive to the hydrometeors as compared to the UHF radars. VHF radar systems often give rise to double trace, corresponding to clear air and hy- drometeors echoes. But this happens only when moderate to heavy precipitation occurs. On the other hand, UHF radars, primarily used for wind observations (Ecklund et al., 1998, 1990), provide an excellent opportunity to investigate the hydrometeor characteristics in the convective systems (Ecklund et al., 1995; Rao et al., 2001). In the present study, colocated VHF and UHF radar observations are used to classify the tropical convective systems as convective, intermediary and or stratiform regions. The intermediary region is an intermediate region between the convective and stratiform region. Classification of the convective systems is very useful for a variety of applications; for example, a vertical profile of diabatic heating of the atmosphere due to the release of latent heat is different in convective and stratiform regions of the tropical convective systems. So, to represent the TMCS in numerical models, it is essential to classify these systems. But the underlying objective of the classification in the present study is to obtain the composite height profiles of the clear air vertical velocity in the convective, intermediary and stratiform regions.

Williams et al. (1995) proposed a method to classify the convective systems. A simple method for classification is to observe the UHF radar power spectra during the passage of TMCS. Figures 12(a-c) show the three distinct types of UHF radar power spectra corresponding to convective, intermediary and stratiform regions, respectively, as observed on 21 June 2000. In the convective region, the Doppler spectrum shows the large hydrometeor velocities and enhanced spectral width. Another distinguished feature of this spectrum is the large hydrometeor fall velocities above the melting layer $\left(0^{\circ} \mathrm{C}\right.$ isotherm). Intermediary region spectrum does not show any enhancement in both the Doppler velocity and the spectral width, on the other hand, the stratiform region spectrum shows a sharp gradient in the Doppler velocity near the melting layer. A peak in the power of the order of 10 to $12 \mathrm{~dB}$ can be noticed in the power spectrum of the stratiform region at $4.2 \mathrm{~km}$, corresponding to the bright band. These UHF radar power spectra are used to classify the observed convective systems into the above mentioned regions. As mentioned 
earlier, the UHF radar observations are available only during August 1997-September 2001; the events observed outside of this period are classified using VHF radar vertical velocity observations (height-time sections). But it is very difficult to exactly identify the intermediary regions from the VHF radar observations. For the present study, the regions appearing immediately after the convective regions have been taken to be the intermediary region. As convective cells go through their natural lifecycles they evolve into a stratiform structure with a bright band. A region of deteriorating convective cells would have an appearance somewhere between that of an active convection and a completely stratiform precipitation, and this region is regarded as intermediary region. Thus, in the present study the intermediary region refers to the transition in time rather than the transition in space. Most of the deep convective systems are classified using this procedure and ultimately the average vertical velocity profiles in these regions are obtained.

\subsection{Composite height profiles of vertical velocities}

As mentioned in Sect. 3.3, each deep convective system is classified into convective, intermediary or stratiform regions and then the vertical velocities are averaged in the respective regions. These vertical velocity profiles in the three regions are obtained for the 14 deep convective systems and are averaged to obtain the composite height profiles. There were some difficulties in identifying the signature of intermediary regions in the three cases. So, only 11 vertical velocity profiles are averaged to obtain the composite vertical velocity profile of the intermediary region. However, the composite height profiles of the vertical velocity in the convective and stratiform regions are averaged for 14 cases. The convective systems observed in the south-west monsoon (June-September) period dominate the present data set. There were slight differences in the shape and magnitude of the vertical velocity height profiles generated from different types of systems. In particular, the magnitudes are different and have shown considerable changes from system to system. Figure 13 shows the composite height profiles of clear air vertical velocities from 4-20 km, as observed by the VHF radar in the convective, intermediary and stratiform regions of the TMCS. For most of the time, the radar was operated using 16-microsecond coded pulse. In this configuration, the radar's first observational range gate starts at $3.6 \mathrm{~km}$. However, for most of the time the first two range gates give obscured values and hence are not included in the present study. We can obtain profiles from $1.5 \mathrm{~km}$ using a $1 \mu$ s pulse, but the height coverage is very poor in this configuration.

Cifelli and Rutledge (1994) reported a detailed study of vertical motion structure of MCS, using $50-\mathrm{MHz}$ profiler data collected during DUNDEE (Rutledge et al., 1992) field programme. In that study, the authors compared composite vertical velocity profiles observed at various locations comprising middle latitude and tropics (both land and ocean). Profiles of the tropical oceanic observation analyzed by Gamache and Houze (1985) and Houze and

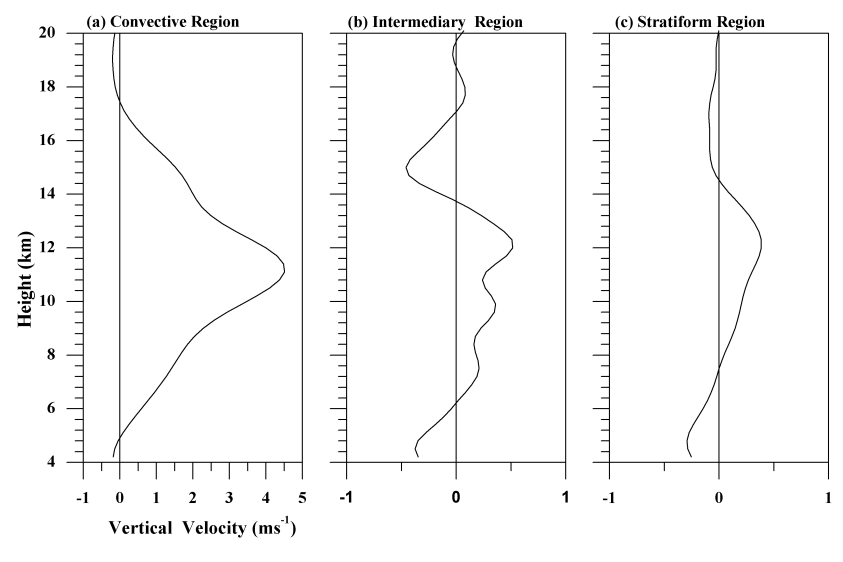

Fig. 13. Composite height profiles of clear air vertical velocities in (a) convective, (b) intermediary and (c) stratiform regions.

Rappaport (1984) in GATE and profiles observed during DUNDEE (Cifelli and Rutledge, 1994) have shown the double peak structure in the convective vertical velocity profiles. But the profiles from the West African tropical continental (Chong et al., 1983) and middle latitude MCS (Biggerstaff and Houze, 1993) have shown a single peak in vertical velocity in the middle troposphere. The convective region profile obtained in the present observations is also very similar to this type, which shows a single peak in the upward motion centered around the mid troposphere $(\sim 11 \mathrm{~km})$. In the convective region profile we saw a downdraft below $4 \mathrm{~km}$, "on average". Here we emphasize the term average, because some individual profiles have shown updrafts at this level. As mentioned above, we have used a $16-\mu$ s coded pulse mode for most of the observations and thus low-level observations were not possible. There is a significant difference in the magnitude of the vertical velocities observed at various geographical locations. One should note here that all these profiles are averaged over different spatial and temporal scales. It is observed that in the convective region, above the freezing level, updrafts will be generally more than that of lower levels. This is because the latent heat released by the freezing of super cooled water drops and by the vapor deposition growth of ice crystals further contribute to the buoyancy and thus to the vertical velocity.

Intermediary and stratiform region vertical velocity profiles were also compared in the same study by Cifelli and Rutledge (1994). The intermediary region profiles observed at various locations have shown a similar type of feature in the lower levels. But there are significant differences in the middle troposphere. The profiles obtained by Houze and Rapport (1984) and Smull and Houze (1987) have shown the ascending motion in the middle to upper troposphere, whereas other profiles, including DUNDEE profile, have shown the descending motion in this region. The intermediary region profile observed in the present study shows descending motion in the lower levels and weak ascending motion in the upper levels, similar to profiles obtained in the middle latitude and tropical oceanic MCS. Stratiform region 
profiles obtained at various locations, including the present profile, have shown more or less similar features, downdrafts in the lower troposphere and weak updrafts in the upper troposphere. In the present study, there is a similarity between the intermediary and stratiform profiles. The stratiform profile looks like a weaker version of the intermedieary profile. The intermediary profile can be interpreted as an early-stage stratiform profile. However, the downdraft at the top of the intermediary profile has yet to be explored in further studies.

In the present study, the composite vertical velocity profile of convective regions shows a peak in the mid troposphere. The altitude of the maximum updraft velocity is quite high. This indicates that the release of latent heat is more at those height regions. These profiles do give us an idea of heating within the convective systems. These vertical velocity profiles are very useful in determining the vertical distribution of diabatic heating in the convective and stratiform regions. These composite vertical velocity height profiles of the convective, intermediary and stratiform regions, which vary from one geographical location to other, have very special implications in the mesoscale modeling and in the convective system simulation studies.

\section{Summary}

The height-time sections of several convective systems are studied to explore their reflectivity, turbulence and vertical velocity structures. The observed systems are classified broadly into convective, intermediary and stratiform regions. Furthermore, the convective parts of the systems are classified into single- and multi-cell systems. It is observed that most of the convective systems are multi-cell systems at this latitude. In the vertical velocity structure of these systems, it is noted that upward velocity cores are separated by narrow downward velocity cores. The downdrafts observed above the freezing level are attributed to the dynamical response, while the downdrafts below this level are mainly due to the precipitation drag and evaporative cooling.

Height-time sections of stratiform regions have shown a characteristic radar bright band at the melting layer. VHF/UHF radar data are used to classify the observed precipitating systems as convective, intermediary or stratiform regions, using a method introduced by Williams et al. (1995). Composite height profiles of vertical velocities in convective, intermediary and stratiform regions are obtained and the same are compared with the profiles obtained at other geographical locations. The convective region composite vertical velocity profile of this location is found to have similarities with both middle latitude and other tropical continental MCS. The present stratiform region profile is consistent with other geographical location profiles, and the intermediary region profiles have shown some dissimilarity in the mid troposphere. These composite height profiles are very useful to understand the latent heat released in the convective systems, to which GCM models are very sensitive. Future work at this latitude will be addressing these problems and will focus attention on simulations and modeling aspects of TMCS.

Acknowledgements. The National MST Radar Facility (NMRF) is operated as an autonomous facility under Department of Space with partial support from Council of Scientific and Industrial Research. The authors are grateful to the NMRF technical staff whose dedicated efforts made possible the observations reported here. UHF radar is setup and being operated at NMRF under joint collaborate programme between India and Japan.

Topical Editor U.-P. Hoppe thanks R. Houze and another referee for their help in evaluating this paper.

\section{References}

Anandan, V. K., Balmuralidhar, P., Rao, P. B., and Jain, A. R.: A method for adaptive moments estimation technique applied to MST radar echoes, Progress in electromagnetic research symposium, Telecommunication research center, City university of Hong Kong, 1996.

Balsley, B. B., Ecklund, W. L., Carter, D. A., Riddle, A. C., and Gage, K. S.: Average vertical motions in the tropical atmosphere observed by a radar wind profiler on Pohnpei $\left(7^{\circ} \mathrm{N}\right.$ latitude, $157^{\circ}$ E longitude), J. Atmos. Sci., 45, 396-405, 1988.

Biggerstaff, M. I. and Houze, R. A. Jr.: Kinematics and microphysics of the transition zone of the 10-11 June 1985 squall line, J. Atmos. Sci., 50, 3091-3110, 1993.

Chong, M., Testud, J., and Roux, F.: Three-Dimensional wind field analysis from dual-Doppler radar data. Part : Minimizing the error due to temporal variation, J. Climate Appl. Meteor., 22, 1216-1226, 1983.

Cifelli R. and Rutledge, S. A.: Vertical motion structure in maritime continent mesoscale, convective systems: Results from 50-MHz profiler, J. Atmos. Sci., 51, 2631-2652, 1994.

DeMaria, M.: Linear response of a stratified tropical atmosphere to convective forcing, J. Atmos. Sci., 42, 113-121, 1985.

Dhaka, S. K., Devarajan, P. K., Shibagaki, Y., Choudhary, R. K., and Fukao, S.: Indian MST radar observations of gravity wave activities associated with tropical convection. J. Atoms. Solar Terr. Phys, 63, 1631-1642, 2001.

Ecklund, W. L., Carter, D. A., Balsley, B. B., Currier, P. E., Green, J. L., Weber, B. L., and Gage, K. S.: Field tests of a lower tropospheric wind profiler, Radio Sci., 25, 899-906, 1990.

Ecklund, W. L., Gage, K. S., and Williams, C. R.: Tropical precipitation studies using $915 \mathrm{MHz}$ wind profiler, Radio Sci., 52, 838-851, 1995.

Ecklund W. L., Carter, D. A., and Balsley, B. B.: A UHF wind profiler for the boundary layer studies: Brief description and initial results, J. Atmos. Oceanic. Technol., 5, 432-441, 1998.

Gage, K. S.: Radar observations of the free atmosphere: Structure and dynamics, Radar in Meteorology, D. Atlas, Ed., Amer. Meteor. Soc., 534-574, 1990.

Gage K. S., Williams, C. R., and Ecklund, W. L.: UHF wind profilers: A new tool for diagnosing tropical convective cloud systems, Bull. Am. Meteorol. Soc., 75, 2289-2294, 1994.

Gage K. S., Williams, C. R., and Ecklund, W. L.: Application of the $915 \mathrm{MHz}$ profiler for diagnosing and classifying tropical precipitating cloud systems, Meteor. Atmos. Phys., 59, 141-151, 1996.

Gamache, J. F. and Houze, R. A. Jr.: Further analysis of the composite wind and thermodynamic structure of the 12 September GATE squall line, Mon. Wea. Rev., 113, 1241-1259, 1985. 
Hack, J. J. and Schubert, W. H.: Some dynamical properties of idealized thermally forced meridional circulations in the tropics, Meteor. Atmos. Phys., 44, 101-117, 1990.

Heymsfield, G. M. and Schotz, S.: Structure and evolution of a sever squall line over Oklahoma, Mon. Wea. Rev., 113, 1563-1589, 1985.

Hartmann, D. L., Hendon, H. H., and Houze, R. A., Jr.: Some implications of the mesoscale circulations in tropical cloud clusters for large-scale dynamics and climate, J. Atmos. Sci., 41, 113-121, 1984.

Houze, R. A., Jr.: Cloud clusters and large-scale vertical motions in the tropics, J. Meteor. Soc. Japan, 60, 396-410, 1982.

Houze, R. A., Jr. and Rappaport, E. N.: Air motions and precipitating structure of an early summer squall line over the eastern tropical Atlantic, J. Atmos. Sci., 41, 553-574, 1984.

Houze, R. A., Jr.: Observed structure of mesoscale convective systems and their implications for large-scale heating, Q.J.R. Meteorol. Soc., 115, 425-461, 1989.

Houze, R. A., Jr.: Cloud dynamics, Academic Press, 1993.

Houze, R. A., Jr.: Stratiform precipitation in regions of convection: A meteorological paradox?, Bull. Am. Meteorol. Soc., 78, 21792196, 1997.

Jain, A. R., Jaya Rao, Y., Anandan, V. K., Rao, P. B., Viswanathan, G., Damle, S. H., Balamuralidhar, P., and Anil Kulakarni: Preliminary observations using ST mode of Indian MST radar: Detection of signature of tropopause, J. Atmos. Terr. Phys., 56, 1157-1162, 1994.

Jain, A. R, Jayarao, Y., Patra, A. K., Rao, P. B., Viswanathan, G., and Subramanian, S. K.: Observations of Tropical convection events using Indian MST Radar: First results Quarterly, J. Royal Met. Soc., 126, 3097-3115, 2000.

Johnson, R. H.: Heat and moisture sources and sinks of Asian monsoon convection, J. Meteor. Soc. Japan, 70, 353-372, 1992.

Jorgensen, D. P. and LeMone, M. A.: Vertical velocity characteristics of oceanic convection, J. Atmos. Sci., 46, 621-640, 1989.

Knupp, K. R.: Downdrafts within high plains cumulonimbi. Part I: General kinematic structure, J. Atmos. Sci., 44, 987-1008, 1987.

Krishna Reddy, K., Kozu, T., Ohno, Y, Nakamura, K., Srinivasulu, P., Anandan, V. K., Jain, A. R., Rao, P. B., Ranga Rao, R., Viswanathan, G., and Rao, D. N.: Lower atmospheric wind profiler at Gadanki, Tropical India: initial result, Meterologische Zeitschrift, 10, 457-466, 2001.

Lemon, L. R. and Doswell C. A. III.: Sever thunderstorm evolution and mesocyclone structure as related to tornadogenesis, Mon. Wea. Rev., 107, 1184-1197, 1979.

Lucas, C., Zipser, E. J., and LeMone, M. A.: Vertical velocity in oceanic convection off tropical Australia, J. Atmos. Sci., 51, 3183-3193, 1994.

Mapes, B. E.: Gregarious tropical convection, J. Atmos. Sci., 50, 2026-2037, 1993.

Mapes, B. E. and Houze, R. A. Jr.: An integrated view of the 1987 Australian monsoon and its mesoscale convective systems. II: Vertical structure, Q. J. R. Meteorol. Soc., 119, 733-754, 1993.

Nicholls, M. E., Pielke, R. A., and Cotton, W. R.: Thermally forced gravity waves in an atmosphere at rest. J. Atmos. Sci., 48, 18691884, 1991.
Rao, T. N., Rao, D. N., and Raghavan, S.: Tropical precipitating systems observed with Indian MST Radar, Radio Sci., Vol., 34(5), 1125-1139, 1999.

Rao, T. N., Rao, D. N., Mohan, K., and Raghavan, S.: Classification of tropical precipitating system and associated Z-R relationships, J. Geophys. Res., 106(D16), 17 699-17 711, 2001.

Rajopadhyaya, D. K., May, P. T., Cifelli, R., Avery, S. K., Williams, C. R., Ecklumd, W. L., and Gage, K. S.: The effect of vertical air motions on rain rates and median volume diameter determined from combined UHF and VHF wind profiler measurements and comparison with rain gauge measurements, J. Atmos. Oceanic Technol., 15, 1306-1319, 1998.

Rao, P. B., Jain, A. R., Kishore, P., Balamuralidhar, P., Damle, S. H., and Viswanathan, G.: Indian MST radar 1, System description and sample vector wind measurements using ST mode, Radio Sci., 30, 1125-1138, 1995.

Rutledge, S. A., Williams, E. R., and Keenan, T. D.: The Down Under Doppler and Electricity Experiment (DUNDEE): Overview and preliminary results, Bull. Am. Meteorol. Soc., 73, 3-16, 1992.

Smull, B. F. and Houze, R. A. Jr.: Dual-Doppler radar analysis of a midlatitude squalline with a trailing region of stratiform rain, J. Atmos. Sci., 44, 2128-2148, 1987.

Trier, S. B., Skamarock, W. C., and LeMone, M. A.: Structure and evolution of the 22 February 1993 TOGA COARE squall line: Organization mechanisms inferred from numerical simulation, J. Atmos. Sci., 54, 386-407, 1997.

Wakasugi, K., Mizutani, A., Matsuo, M., Fukao, S., and Kato, S.: A direct method for deriving drop-size distribution and vertical air velocities from VHF Doppler radar spectra, J. Atmos. Oceanic. Technol., 3, 623-629, 1986.

Wakasugi, K., Mizutani, A., Matsuo, M., Fukao, S., and Kato, S.: Further discussion on deriving drop-size distribution and vertical air velocities directly from VHF Doppler radar spectra, J. Atmos. Oceanic. Technol., 4, 170-179, 1987.

Weisman, M. L. and Klemp, J. B.: The structure and classification of numerically simulated convective storms in directionally varying wind shears, Mon. Weather Rev., 112, 2479-2498, 1984.

Williams, C. R., Ecklund, W. L., and Gage, K. S.: Classification of precipitating clouds in the tropics using $915-\mathrm{MHz}$ wind profilers, J. Atmos. Oceanic. Technol., 12, 996-1012, 1995.

Yuter, S. E. and Houze, R. A. Jr.: Three-dimensional kinematics and microphysical evolution of Florida cumulonimbus. Part I: spatial distribution of updrafts, downdrafts and precipitation, Mon. Wea. Rev., 123, 1921-1940, 1995a.

Yuter, S. E. and Houze, R. A. Jr.: Three-dimensional kinematic and microphysical evolution of Florida cumulonimbus. Part : Frequency distribution of vertical velocity, reflectivity, and differential reflectivity, Mon. Wea. Rev., 123, 1941-1963, 1995b.

Zipser, E. J., Betts, A., Ruggiero, F., and Hinton, B.: Tropical meteorology: Panel report, Radar in Meteorology, D.Atlas, Ed., Amer. Meteor. Soc., 426-434, 1990. 